\title{
One-Visit Apexification in Management of Gutta Percha Extrusion and Condensing Osteitis: 4 Years Follow-Up
}

\author{
Rasda Diana ${ }^{1, *}$ Andina Widyastuti ${ }^{2}$ Pribadi Santosa ${ }^{3}$ \\ ${ }^{1}$ Specialist Study Program of Conservative Dentistry, Faculty of Dentistry Universitas Gadjah Mada Yogyakarta, Indonesia \\ ${ }^{2,3}$ Department of Conservative Dentistry, Faculty of DentistryUniversitas Gadjah MadaYogyakarta, Indonesia \\ *Corresponding author. Email: rasda.diana@gmail.com
}

\begin{abstract}
An overfilled root canal is the most common iatrogenic error in daily endodontic practice, especially on open apex tooth, which leads to chronic periapical inflammation and failure of endodontic therapy. With various materials and techniques available, the clinician must determine the ideal protocol to ensure successful endodontic treatment. This case report evaluates the outcome of the non-surgical, one-visit apexification using Mineral Trioxide Aggregate (MTA) of first maxillary incisor with an overfilled root canal, open apex, and condensing osteitis after four years follow-up. A 27-years-old woman was referred to Universitas Gadjah Mada Dental Hospital Yogyakarta due to biting pain and discoloration on first maxillary incisor with a history of trauma and endodontic treatment over 10 years ago. Periapical radiographs showed an overfilled open apex with condensing osteitis on the surrounding of the apex. Conventional endodontic retreatment was performed, followed by one-visit apexification using MTA. After 6 weeks, the biting pain relieved. Obturation and intracoronal bleaching then proceeded. Class IV composite was completed as a final restoration after 8 weeks of apexification. After 4 years follow-up, there was no sign and symptom and the condensing osteitis diameter reduced which indicated a successful treatment. This case supports the long-term evidence of former findings of the role of case selection, technique, and usage of MTA as one-visit apexification materials after a year follow-up. Furthermore, it provides a new perspective on the effect of MTA in the management of condensing osteitis. One-visit apexification using MTA is considered effective in the management of condensing osteitis due to gutta-percha extrusion in the long term
\end{abstract}

Keywords: apexification, overfilled, endodontic, MTA

\section{BACKGROUND}

Key learning points:

- MTA creates alkaline environment which prevent tooth resorption

- Despite favourable properties of MTA, a mild discoloration post walking bleach was found after 4 years

- In young adult patients, dental trauma could lead to pulp necrosis, discoloration and disruption of apex formation

- In tooth with incomplete root and condensing osteitis, MTA could provide apical seal. However, it did not completely resolve the condensing osteitis after 4 years.

Dental trauma incident occurred about $4.5 \%$ annually worldwide for both children and adults. Most cases involve central maxillary incisor [1]. On young adult patient, traumatic dental injuries could cause a necrotic pulp in which disrupted apex maturation [2]. The loss of apical constriction makes it difficult to perform a proper endodontic treatment especially the application of filling material. As the consequence, the incident of overfilling may occur. This overfilled condition may harm the main objective of endodontic treatment, which is to eliminate infection and symptoms [3]. Extruded filling materials may induce a foreign body reaction and an inflammatory response which lead to several complications such as pain, swelling, granuloma formation, paresthesia, periapical lesion, and also endodontic failure [4-6]. Furthermore, this case presented a unique finding of condensing osteitis formation as a result of constant periapical inflammation.

Recently there are two approaches in managing an overfilled root canal which are surgical and non-surgical method such as revascularization and apexification [7-11]. Apexification is defined as the application of barrier upon an open apex which involves cleansing of the necrotic pulp, root canal debridement and application of intracanal medicament [12]. Calcium hydroxide and MTA are two widely used materials in apexification $[8,13]$. In spite of the sealing ability of calcium hydroxide, there are several drawbacks such as the time length, unpredictable calcific barrier formation, and increase fracture susceptibility [1416]. Therefore, recently MTA has gained popularity as a material of choice for apexification. MTA has good biocompatibility, high $\mathrm{pH}$ which affects its antimicrobial properties, excellent sealing ability, and shortening the treatment time compared to calcium hydroxide [12]. However, it has not been widely discussed the effect of MTA towards condensing osteitis on immature tooth. This article presents a 4-years follow up of apexification using 
MTA on immature tooth with an overfilled root canal and condensing osteitis.

The goal of this case report is to develop a more rigorous understanding of management of gutta percha (GP) extrusion on immature tooth with condensing osteitis using MTA. Furthermore, walking bleach technique is also presented.

\section{METHODS}

\subsection{Case Report}

A 27-years-old woman was referred to the endodontic unit of Universitas Gajdah Mada Dental Hospital Yogyakarta, Indonesia for evaluation and management of biting pain and discoloration on first maxillary right incisor. Patient had a history of motorcycle accident which caused a tooth fracture and recurrence throbbing pain approximately 10 years ago. However, patient did not go to the dentist until 5 years later. Endodontic treatment was performed by the previous dentist followed by composite resin restoration. Nevertheless, after 5 years, patient still experiencing biting pain. Furthermore, the tooth became darker. Percussion test revealed positive response and there was no tenderness on palpation. Radiographic examination showed an overfilled GP extended beyond the apex surrounded by a radiopaque area with a diameter around 6,7 $\mathrm{mm}$. Based on these findings, it was determined that the periodontitis is caused by the overfilled GP and that the gray discoloration was intrinsic and could not be removed by prophylaxis paste. After rubber dam placement, access opening was performed using an endo access diamond bur (Dentsply). Preoperative radiograph was used to measure working length estimation. GP then removed using \#55 Hedström file. Afterwards, working length was confirmed using periapical radiograph. Biomechanical preparation was done using conventional method (K-file \#55, \#60, \#70, $\# 80$ ) and root canal debridement was performed using $2.5 \%$ $\mathrm{NaOCl}$ and saline simultaneously. The root canal was then dried with sterile paper points. MTA placement was done using MAP system followed by periapical radiograph examination. Temporary filling material was then placed.

Six weeks later, patient was recalled. There was no symptom persists upon control. GP then sterilized using $2.5 \% \mathrm{NaOCl}$, alcohol $70 \%$, and saline subsequently. The root canal irrigation was done using $2.5 \% \mathrm{NaOCl}$ followed by saline then dried using sterile paper point. Root canal obturation was done using lateral condensation technique with resin based sealer (Topseal, Dentsply). Temporary restoration was then placed followed by periapical radiograph examination (Fig 1B-D).

Following the apexification, walking bleach technique was performed a week later. After removal of $2 \mathrm{~mm}$ GP below the orifice, resin modified glass ionomer cement (RMGIC) (Fuji II LC, GC) was placed as a cervical barrier with a thickness approximately $0.5 \mathrm{~mm}$. Periapical radiograph was performed to ensure the thickness of the periapical barrier. A 35\% hydrogen peroxide (Opalescence Endo, Ultradent) was then placed as a bleaching agent followed by a double seal using cavit (Caviton, GC) and RMGIC (Fuji II LC, GC). After 3 days patient came back with no symptom and improved tooth colour. The tooth shade enhanced from C4 to A3 (Vita classic shade guide) which similar to other teeth colours. Temporary filling was then removed and the cavity was rinsed using warm saline. A mixture of calcium hydroxide and saline was placed at the cavity to neutralize the free radicals from the bleaching agent.

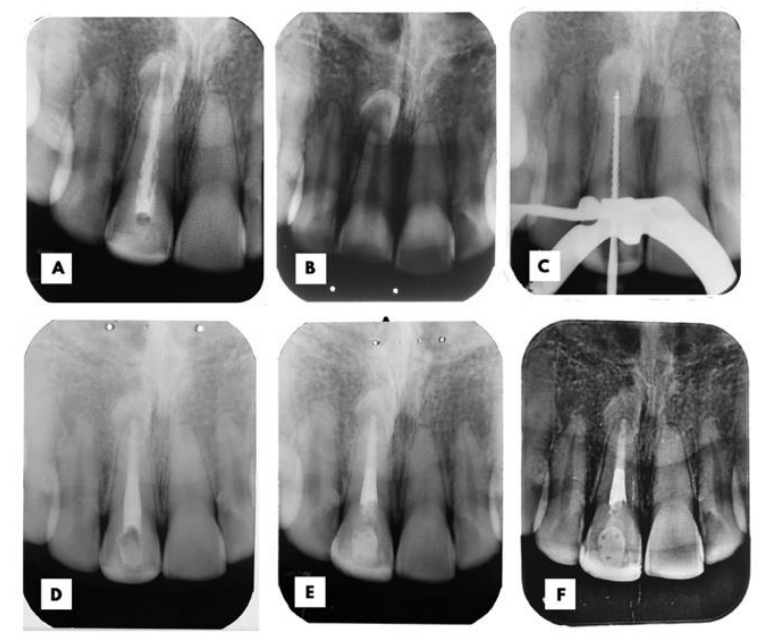

Figure 1. Radiographic appearance: (A) Initial condition, (B-D) One step apexification prodecure, (E) Final restoration, $(\mathrm{F})$ After 4 years follow-up

A week later, patient came back to do the final restoration. The tooth remains asymptomatic. The temporary restoration and the remaining calcium hydroxide was then removed. Tooth preparation was performed using round-end tapered diamond bur then followed by a pearshaped diamond bur to create a bevel at the palatal. The tooth then was etched for 15 seconds at enamel depth and 10 seconds at dentin depth (DenFil ${ }^{\mathrm{TM}}$ Etchant-37, Vericom Co., Ltd., Korea). Afterwards, a $5^{\text {th }}$ generation bonding agent (Stae, SDI Limited, Australia) was applied using microbrush and let it rested for 20 seconds followed by curing using light curing unit for 10 seconds. A microhybrid composite resin shade A2 (Filtek ${ }^{\mathrm{TM}}$ Z250, 3M ESPE USA) was placed using incremental technique which then activated using a light curing unit for 20 seconds. After occlusal adjustment, restoration finishing and polishing was performed using fine finishing diamond bur and polishing point (Ehance, Dentsply) subsequently. Patient came back a week later and there was no symptoms, the restoration remain intact and no traumatic occlusion.

Four years later, patient was recalled. The restoration had slight discoloration (Fig 2), however there was no tenderness on percussion and palpation on tooth 11 . Nevertheless, patient complained that sometimes she experienced mild throbbing pain on her front maxillary 
teeth in which she did not sure which tooth is it. Further radiographic examination showed that there was no resorption, however, the condensing osteitis remained on apical tooth 11 and a possible fracture appearance showed on the root of tooth 21 (Fig 1).

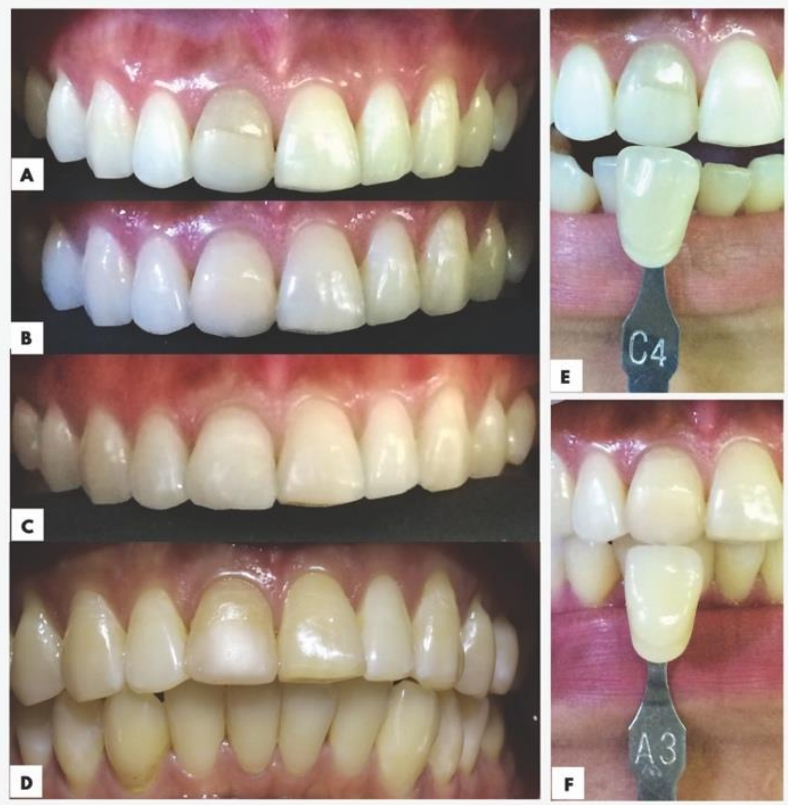

Figure 2. Treatment progress: (A) Intital condition, (B) After walking bleach, (C) Restoration, (D) After 4 years, (E) Shade guide selection on initial visit, (F) Shade guide selection after walking bleach

\section{DISCUSSION}

\subsection{Treatment}

Gutta percha extrusion might happened due to root resorption, incorrect working length measurement, or incomplete formation of root apex [17]. In this case, dental trauma that happened to the patient while she was young, caused pulp necrosis and incomplete root development. The loss of apical constriction was probably the cause of possible over instrumentation which lead to rot canal over filing by the previous dentist. The effect of extruded GP may vary. It is often lead to resorption of apical root [17]. Santoro et.al [18] reported two cases of persistent pain due to extrusion of root canal filling materials. Both of them were resolved after periapical surgery. While [19], reported finding of swelling, pus formation, persistent pain and cyst formation due to GP extrusion on young patient. Similar with Santoro et.al, the GP extrusion were managed by periapical surgery. Others reported paresthesia and also chronic sinusitis related to extruded filling materials $[5,6]$.

Meanwhile, this case presented condensing osteitis as an inflammatory response towards GP extrusion. Condensing osteitis is a condition where trabecular bone density increases as a response to persistent inflammation [12]. In this case, this might occur due to the extrusion of the GP.
Gutta percha might be recognized as a foreign body and induced inflammation [19]. However, Bergenholtz et.al [20] argued that extruded filling materials is not directly related to the failure of endodontic treatment, instead over instrumentation is the major cause, which lead to persistent infection.

Apexification was chosen instead of periapical surgery, because it facilitates the closure of the apex without compromising the crown-root ratio. Apexification has proven to not only induced apical closure but also increase crown-root ratio on immature teeth [21,22]. Furthermore, revascularization was not an option due to the presence of condensing osteitis. Lin et al., [22] reported that both revascularization and apexification has similar result in regard to the apical healing and symptom improvement. In addition, cohort studies by Alobaid et al., [23] showed that in both clinical and radiographical evaluation, revascularization was not superior compared to apexification.

One-step apexification using MTA was performed. Mineral trioxide aggregate was used because it allowed shorter treatment duration. Lin et al., [24] reported that both calcium hydroxide and MTA has similar success rate in apexification. However, MTA provides better overall rate due to shorter treatment time. Moreover, Shrikrishna, Shah and Vivekananda Pai [19] reported that MTA is able to resolve endodontic failure related to over instrumentation and over filled GP. MTA which consist of mainly calcium and silicate, works on several mechanisms:

1. The alkaline $\mathrm{pH}$ provides antibacterial environment

2. Release calcium ion which important for cell attachment and proliferation

3. Induces differentiation and migration of osteoblast

4. Produces hydroxyapatite or carbonated apatite which act as a biologic seal

\section{Increase cytokine production [25].}

Moreover, dentoalveolar trauma may cause bleeding within pulp chamber. As a consequence, blood components diffused into dentinal tubules. The hemolysis of red blood cells induced the release of heme which then contacted with pulpal tissue and forming iron. Hydrogen sulfates from bacteria, was then turn the iron into iron sulfates which is a dark component and caused greyish discoloration on the entire tooth [26-28]. Therefore, walking bleach technique was performed. RMGIC was used as a cervical barrier. Oskoee et al., [29] reported that the usage of other materials as cervical barrier combined with different intracanal bleaching materials showed similar result to RMGIC in terms of fracture resistance. The walking bleach technique was performed because it has shown to be able to resolve intrinsic discoloration caused by pulpal hemorrhage $[26,30]$. Furthermore, compared to inside-outside technique, walking bleach technique showed similar results 
even after a year [31]. Moreover, a 35\% hydrogen peroxide was used as a bleaching agent because it has proven in improving color on discolored necrotic tooth [32-34]. Furthermore, Devji [30] reported that bleaching with hydrogen peroxide improved color change significantly as well as patient satisfactory. Moreover, tooth 21 condition were favorable for direct resin composite restoration. The crown-root ratio was sufficient. In addition, resin composite was used as a final restoration due to its favorable esthetic, ability to bond to enamel, perseverance of tooth structure, longevity, similar wear rate with enamel and shorter treatment duration [35].

\subsection{Treatment Result}

After 4 years, there was no sign and symptom reported by the patient. There was no tenderness on both percussion and palpation. This result is in line with the study conducted by Lin, Rosenberg and Lin [17] which reported that $76 \%$ cases of extruded gutta percha were resolved after proper endodontic retreatment. Although from clinical perspective it could be indicated that the treatment was a success, radiographic imaging showed persistence of condensing osteitis. The diameter of condensing osteitis was reduced from $6,7 \mathrm{~mm}$ to $5,7 \mathrm{~mm}$. It is contradictory towards theory by Torabinejad and Walton [12] which stated that condensing osteitis may completely resolved after root canal treatment.

The persistence of condensing osteitis might also contribute to the ability of MTA to perform apical closure. There was no significant increase in both dentinal wall thickness and also the rate of apical closure on tooth 21. This result differs from previous cases reported on immature teeth which reported complete apical closure after apexification using MTA [24,36]. However, from previously reported cases, there was no findings on condensing osteitis as an inflammatory response. Moreover, the walking bleach showed color improvement as soon as 3 days. This result is in line with study reported by Tran et al., [37] which stated that the minimum replacement interval of hydrogen peroxide is 3 days. It is based on the chemistry of the reduction of the hydrogen peroxide. The mild discoloration on composite resin restoration might happened due to microleakage of composite. The microleakage allows chemical stain to penetrate between tooth structure and restoration. Besides, time might cause discoloration on resin composite [12].

\section{CONCLUSION}

One-step apexification using MTA has proven to be able to resolve sign and symptom of pain due to extruded GP on immature tooth. This study indicates that one-step apexification might be an option to treat GP extrusion on immature tooth comparet to surgical method. Further study needed to investigate the effect of MTA on condensing osteitis.

\section{REFERENCES}

[1] Lam R. Epidemiology and outcomes of traumatic dental injuries: A review of the literature. Aust Dent $\mathbf{J}$ 2016;61:4-20. https://doi.org/10.1111/adj.12395.

[2] Yu CY, Abbott P V. Responses of the pulp, periradicular and soft tissues following trauma to the permanent teeth. Aust Dent J 2016;61:39-58. https://doi.org/10.1111/adj.12397.

[3] Chugal N, Mallya SM, Kahler B, Lin LM. Endodontic Treatment Outcomes. Dent Clin North Am 2017;61:59-80.

https://doi.org/10.1016/j.cden.2016.08.009.

[4] GLUSKIN AH. Anatomy of an overfill: a reflection on the process. Endod Top 2007;16:64-81. https://doi.org/10.1111/j.1601-1546.2009.00238.x.

[5] González-Martín M, Torres-Lagares D, GutiérrezPérez JL, Segura-Egea JJ. Inferior alveolar nerve paresthesia after overfilling of endodontic sealer into the mandibular canal. J Endod 2010;36:1419-21. https://doi.org/10.1016/j.joen.2010.03.008.

[6] Kim J-W, Cho K-M, Park S-H, Park S-R, Lee S-S, Lee S-K. Chronic maxillary sinusitis caused by root canal overfilling of Calcipex II. Restor Dent Endod 2014;39:63. https://doi.org/10.5395/rde.2014.39.1.63.

[7] Kim JE, Cho JB, Yi WJ, Heo MS, Lee SS, Choi SC, et al. Accidental overextension of endodontic filling material in patients with neurologic complications: A retrospective case series. Dentomaxillofacial Radiol 2016;45:1-6. https://doi.org/10.1259/dmfr.20150394.

[8] Witherspoon DE, Small JC, Regan JD, Nunn M. Retrospective Analysis of Open Apex Teeth Obturated with Mineral Trioxide Aggregate. J Endod 2008;34:1171-6.

https://doi.org/10.1016/j.joen.2008.07.005.

[9] Oliveira TM, Sakai VT, Silva TC, Santos CF, Abdo RCC, MacHado MAAM. Mineral trioxide aggregate as an alternative treatment for intruded permanent teeth with root resorption and incomplete apex formation. Dent Traumatol 2008;24:565-8. https://doi.org/10.1111/j.1600-9657.2008.00577.x.

[10] Wigler R, Kaufman AY, Lin S, Steinbock N, HazanMolina H, Torneck CD. Revascularization: A treatment for permanent teeth with necrotic pulp and incomplete root development. J Endod 2013;39:31926. https://doi.org/10.1016/j.joen.2012.11.014.

[11] Jacobovitz M, De Pontes Lima RK. The use of calcium hydroxide and mineral trioxide aggregate on apexification of a replanted tooth: A case report. Dent Traumatol 2009;25:32-6. https://doi.org/10.1111/j.1600-9657.2008.00745.x.

[12] Torabinejad M, Walton RE. Endodontic Principles and Practice. 4th ed. St. Louis: Saunders Elsevier; 2002. 
[13] Soares J, Santos S, César C, Silva P, Sá M, Silveira F, et al. Calcium hydroxide induced apexification with apical root development: A clinical case report. Int Endod $\mathrm{J}$ 2008;41:710-9. https://doi.org/10.1111/j.1365-2591.2008.01415.x.

[14] Patel B, editor. Endodontic Treatment, Retreatment, and Surgery. Springer; 2016. https://doi.org/10.1007/978-3-319-19476-9_13.

[15] N R, Chandra S.M S. Merits and Demerits of Calcium Hydroxide as a Therapeutic Agent: A Review. Int J Dent Sci Res 2014;2:1-4. https://doi.org/10.12691/ijdsr-2-6b-1.

[16] Ba-Hattab R, Al-Jamie M, Aldreib H, Alessa L, Alonazi M. Calcium Hydroxide in Endodontics: An Overview. Open J Stomatol 2016;06:274-89. https://doi.org/10.4236/ojst.2016.612033.

[17] Lin LM, Rosenberg PA, Lin J. Do procedural errors cause endodontic treatment failure? J Am Dent Assoc 2005;136:187-93. https://doi.org/10.14219/jada.archive.2005.0140.

[18] Santoro V, Lozito P, Donno A De, Grassi FR, Introna F. Extrusion of Endodontic Filling Materials: MedicoLegal Aspects. Two Cases. Open Dent J 2009;3:6873. https://doi.org/10.2174/1874210600903010068.

[19] Shrikrishna S, Shah N, Vivekananda Pai A. Surgical management of overfilled gutta-percha and root capping with mineral trioxide aggregate in a young patient. J Interdiscip Dent 2014;4:148. https://doi.org/10.4103/2229-5194.147336.

[20] Bergenholtz G, Lekholm U, Milthon R, Engstrom B. Influence of apical overinstrumentation and overfilling on re-treated root canals. J Endod 1979;5:310-4. https://doi.org/10.1016/S0099-2399(79)80080-1.

[21] Silujjai J, Linsuwanont P. Treatment Outcomes of Apexification or Revascularization in Nonvital Immature Permanent Teeth: A Retrospective Study. J Endod https://doi.org/10.1016/j.joen.2016.10.030. 2017;43:238-45.

[22] Lin J, Zeng Q, Wei X, Zhao W, Cui M, Gu J, et al. Regenerative Endodontics Versus Apexification in Immature Permanent Teeth with Apical Periodontitis: A Prospective Randomized Controlled Study. J Endod 2017;43:1821-7. https://doi.org/10.1016/j.joen.2017.06.023.

[23] Alobaid AS, Cortes LM, Lo J, Nguyen TT, Albert J, Abu-Melha AS, et al. Radiographic and clinical outcomes of the treatment of immature permanent teeth by revascularization or apexification: A pilot retrospective cohort study. J Endod 2014;40:1063-70. https://doi.org/10.1016/j.joen.2014.02.016.

[24] Lin JC, Lu JX, Zeng Q, Zhao W, Li WQ, Ling JQ. Comparison of mineral trioxide aggregate and calcium hydroxide for apexification of immature permanent teeth: A systematic review and meta-analysis. J
Formos Med Assoc 2016;115:523-30. https://doi.org/10.1016/j.jfma.2016.01.010.

[25] Parirokh M, Torabinejad M. Mineral Trioxide Aggregate: A Comprehensive Literature Review-Part III: Clinical Applications, Drawbacks, and Mechanism of Action. J Endod 2010;36:400-13. https://doi.org/10.1016/j.joen.2009.09.009.

[26] Plotino G, Buono L, Grande NM, Pameijer CH, Somma F. Nonvital Tooth Bleaching: A Review of the Literature and Clinical Procedures. J Endod 2008;34:394-407. https://doi.org/10.1016/j.joen.2007.12.020.

[27] Manuel S, Abhishek P, Kundabala M. Etiology of tooth discoloration- a review. Nig Dent J 2010;18:5663.

[28] Nathoo SA. The chemistry and mechanisms of extrinsic and intrinsic discoloration. J Am Dent Assoc 1997;128:6S-10S. https://doi.org/10.14219/jada.archive.1997.0428.

[29] Oskoee SS, Bahari M, Daneshpooy M, Ajami AA, Rahbar M. Effect of Different Intraorifice Barriers and Bleaching Agents on the Fracture Resistance of Endodontically Treated Anterior Teeth. J Endod 2018:44:1731-5. https://doi.org/10.1016/j.joen.2018.07.025.

[30] Devji T. Walking bleach technique for endodontically treated teeth with $35 \%$ hydrogen peroxide and $37 \%$ carbamide peroxide may result in similar improvements in tooth color and patient satisfaction. $\mathbf{J}$ Am Dent Assoc 2018;149:e113. https://doi.org/10.1016/j.adaj.2018.02.003.

[31] Pedrollo Lise D, Siedschlag G, Bernardon JK, Baratieri LN. Randomized clinical trial of 2 nonvital tooth bleaching techniques: A 1-year follow-up. J Prosthet Dent 2018;119:53-9. https://doi.org/10.1016/j.prosdent.2017.03.004.

[32] A.R. B, M.C. V, M.N.G. M, C.B. M, I. B. In vitro penetration of bleaching agents into the pulp chamber. Int Endod J 2004;37:120-4.

[33] Parreiras S, Vianna P, Kossatz S, Loguercio A, Reis A. Effects of Light Activated In-office Bleaching on Permeability, Microhardness, and Mineral Content of Enamel. Oper Dent 2014;39:E225-30. https://doi.org/10.2341/13-031-1.

[34] Kwon SR, Wertz PW. Review of the mechanism of tooth whitening. J Esthet Restor Dent 2015;27:240-57. https://doi.org/10.1111/jerd.12152.

[35] Chan KHS, Mai Y, Kim H, Tong KCT, Ng D, Hsiao JCM. Review: Resin composite filling. Materials (Basel) 2010;3:1228-43. https://doi.org/10.3390/ma3021228.

[36] Matović I, Ilić D V., Petrović R, Ostojić D. The application of MTA as apical plug for root canal 
obturation - in vitro ...: EBSCOhost. Article 2008;65. https://doi.org/10.2478/sdj-2018-0007.

[37] Tran L, Orth R, Parashos P, Tao Y, Tee CWJ, Thomas VT, et al. Depletion Rate of Hydrogen Peroxide from Sodium Perborate Bleaching Agent. J Endod 2017;43:472-6.

https://doi.org/10.1016/j.joen.2016.10.043. 